\title{
The Effect of Pollution on the Insulators Performance in High Voltage Transmission Lines
}

\author{
Olfat R. Abd Eljwaad \\ Faculty of Engineering \\ Helwan University \\ Cairo, Egypt
}

\author{
M.K. Abd Elrahman \\ Faculty of Engineering \\ Helwan University \\ Cairo, Egypt
}

\author{
M.Kh. Mohamed \\ Faculty of Engineering \\ Helwan University \\ Cairo, Egypt
}

\begin{abstract}
This paper investigates the simulation results of the electric field distributions along silicone rubber insulator surfaces with different designs and under different pollution conditions. The first model consists of four uniform sheds and the second model consists of five alternative sheds. In order to study the effects of different types of pollution layers like (sand, water-saturated sand, and nitrogen dioxide) on the electric field over the creepage distance with thickness 0.1 $\mathrm{cm}$. the maximum electric fields in water-saturated sand 130 $\mathrm{kV} / \mathrm{m}$ in the first model and $129 \mathrm{kV} / \mathrm{m}$ in the second model, in case of air with dry sand $110 \mathrm{kV} / \mathrm{m}$ in the first mode and 90 $\mathrm{kV} / \mathrm{m}$ in the second model, in pure air $95 \mathrm{kV} / \mathrm{m}$ in the first model and $73 \mathrm{kV} / \mathrm{m}$ in the second model. According to the explosion ammonium nitrate, the maximum electric field in both models $220 \mathrm{KV} / \mathrm{m}$ when the air is polluted with nitrogen dioxide and the maximum electric field in case the pollution layer in the insulator is $360 \mathrm{kV} / \mathrm{m}$ in the first model and 185 $\mathrm{kV} / \mathrm{m}$ in the second model. (COMSOL multiphasic 5.5) software programs have been used for calculating and comparing different types of pollution based on the finite element method (FEM).
\end{abstract}

\section{Keywords}

Silicon rubber insulators, finite elements method, pollution on insulators, 2D and 3D insulator models, ammonium nitrate, nitrogen oxide, sand, water-saturated sand

\section{INTRODUCTION}

Insulators are considered one of the main important components in the transmission lines and networks and they effectively constitute the operating and maintenance costs of these networks [1]. The insulators are exposed to electrical stresses because of operating stress and also because of the electric impulses resulting from a thunderstorm or internal overvoltage due to separation and connection processes. The insulators must withstand these electrical stresses under various environmental, weather, and operational conditions [2]. The operational experiences and statistics have shown that the faults are caused by the inability of the insulators to withstand normal operational efforts under pollution conditions. It represents the largest percentage of the total faults in transmission lines and may reach more than $80 \%$ in some Arab countries therefore, the most important factor that determines the insulation design in these areas is Insulators withstand electrical operating voltages under prevailing pollution conditions $[3,4,5]$. The problem of polluted the surface of insulators occurs due to the accumulation of pollutants suspended in the air on these surfaces [6].

The pollution problem with insulators depends mainly on two factors:
1-The difference between the rate of accumulation of pollution materials on the surfaces of insulators and the rate of removal of those materials by the ability of insulators to selfcleaning by wind or by rain, depending on the weather conditions, the shape of the insulator, the type of pollution materials and components, and electric fields.

2-The moisture rate of the surfaces of the insulators, which depends on the weather conditions, especially the relative humidity, fog, dew, and light rain mist. The shape of the insulator affects the speed of the humidification and consequently the conductivity of the pollution layer.

The electrical performance of silicone rubber insulators is higher than glass and porcelain insulators. It also has superior insulation that does not allow water to contact with pollution on the insulator, which limits the susceptibility of these insulators to pollution. [7].

One of the factors that may affect the performance of insulators ammonium nitrate, and it's a white granule that is odorless like salt. Ammonium nitrate is not in itself a risk, according to the German website (Chemie.de). It depends on the storage method and the safety standards followed. Ammonium nitrate becomes explosive if large amounts of it are stored close to each other In this case, the ammonium nitrate is heated and ignited if the amount stored is very large, and then it reacts with oxygen that increases its ignition power. After ignition, ammonium nitrate begins to melt, and a solid layer forms around it while the material continues to burn inside this layer, similar to an eruption of a volcano as the gases formed from the combustion of the material pressure on the outer solid layer until it explodes chemicals from the explosion dissipate quickly in the atmosphere, but some pollutants may still be present such as nitrogen oxide, which causes a red cloud over the site of the explosion. [8]

\section{METHODOLOGY}

The proposed designs are simulated using Finite Element Method (FEM) and (COMSOL Multiphasic 5.5) in order to investigate the effect of different pollution types like dry sand, water-saturated sand, and ammonium nitrate. The effect of ammonium nitrate explosion on the insulators in the electric power transmission lines has been simulated by using assuming pollution layer on the insulator surface and by assuming polluted air around the insulator.

\subsection{First step: the geometry}

In this paper, two different insulator design have been used, 4 sheds uniform insulator and 5 sheds alternative insulator as shown in table1. in order to simulate composite insulators. [9] 
Table 1. The dimensions of parts of the composite insulator

\begin{tabular}{|c|c|c|}
\hline Structure parameters & Model 1 & Model 2 \\
\hline Shed type & Uniform & Alternating \\
\hline Creepage distance $(\mathrm{mm})$ & 430 & 495 \\
\hline Arcing distance $(\mathrm{mm})$ & 180 & 188 \\
\hline Sectional length $(\mathrm{mm})$ & 360 & 318 \\
\hline Core thickness $(\mathrm{mm})$ & 18 & 16 \\
\hline No. of sheds & 4 & 5 \\
\hline Shed diameter $(\mathrm{mm})$ & 85 & $134 / 105$ \\
\hline Shed spacing $(\mathrm{mm})$ & 43 & 100 \\
\hline End fitting diameter $(\mathrm{mm})$ & 40 & 46 \\
\hline \multicolumn{2}{|c}{}
\end{tabular}

In the geometry stage, 2D axis symmetry as a spatial dimension as shown in figure 1 is used to achieve 3D structure for more realism. The proposed designs are built using COMSOL geometry tools as shown in figure 2 . Where each $3 \mathrm{D}$ model is revolved $\left(360^{\circ}\right)$ from the $2 \mathrm{D}$ plane.

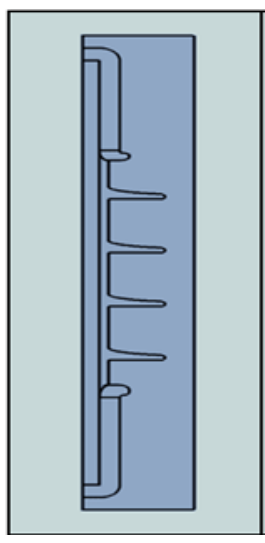

(a)

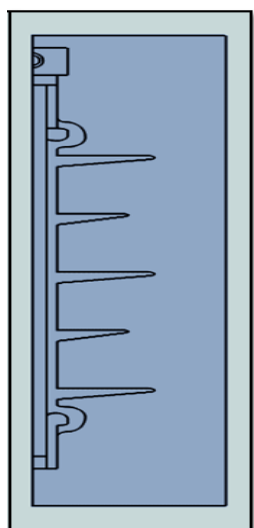

(b)
Fig 1: 2D plane of axis symmetry of the proposed designs: a) four uniform sheds b) five alternative sheds (a)

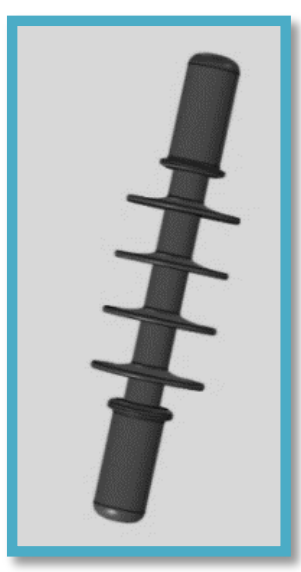

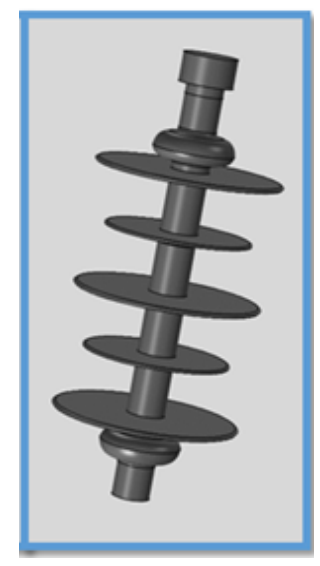

(b)
Fig 2: 3D revolving of the proposed designs a) four uniform sheds b) five alternative sheds

\subsection{Second step: the selection of material properties}

According to the selected physics, there are required features to solve the related equations. In this study, the AC current module is proposed to simulate and calculate the generated electric field. So, the permittivity and conductivity features of different materials of the composite insulator are required as shown in Table 2. [10,11]

Table .2 the material properties of each part of the insulator

\begin{tabular}{|c|c|c|}
\hline Material & $\begin{array}{c}\text { Relative } \\
\text { permittivity } \varepsilon_{r}\end{array}$ & $\begin{array}{c}\text { Conductivity } \\
\boldsymbol{\sigma}(\mathbf{S} / \mathbf{m})\end{array}$ \\
\hline Forged steel & 1 & $5.9 \times 107$ \\
\hline Air & 1 & $1 \times 10-13$ \\
\hline Silicone rubber & 4.3 & $1 \times 10-12$ \\
\hline FRP core & 7.2 & $1 \times 10-12$ \\
\hline Pollution layer & 4.1 & $6.0 \times 10-7$ \\
\hline $\begin{array}{c}\text { Water saturated } \\
\text { sand }\end{array}$ & 25 & 0.03 \\
\hline Dry sand & 4 & 0.01 \\
\hline nitrogen oxide & 1.46 & \\
\hline
\end{tabular}

\subsection{The third step: the meshing}

To solve the previous equations and generate results over the whole structure, the structure should divide into elements each element consists of nodes At these nodes, the equations are solved and predicted over the element in order to generate a distribution of the results over the whole structure. In this study, a free triangular element is proposed, and the size of the element is refined at the creepage distance as marked with blue as shown in Figure 3 in order to increase the accuracy of results at this edge.

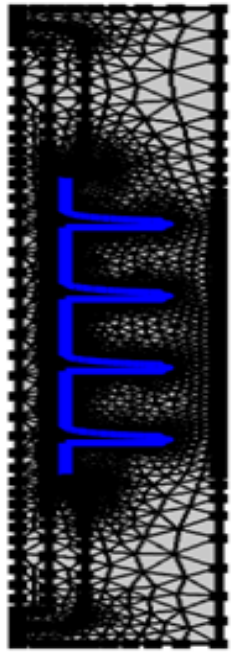

(a)

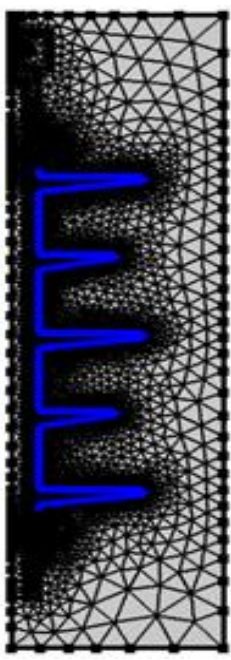

(b)
Fig 3: The meshing a) model 1 b) model 2

\section{RESULTS}

The work reported in this paper refers to the calculation of the electric field on an insulator with pollution and without pollution using the finite element method.

\subsection{D Model}

The applied electric potential to the proposed insulator is shown in Figure 4. The rainbow legend bar range between the 
maximum value $(11 \mathrm{kV})$ and the minimum value (ground) which is represented by the red color and blue respectively.

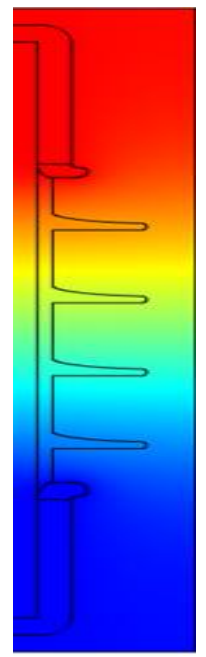

(a)

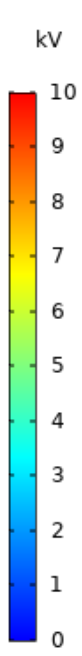

(b)

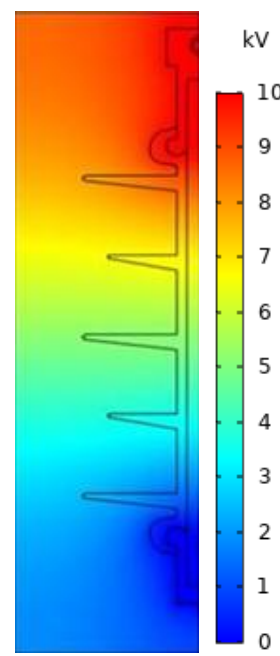

Fig 4: Electric potential a) model 1 b) model 2

The generated electric field distribution over the whole insulator. The red color represents the highest values of the electric field which is localized at the start and the end of the creepage distance.

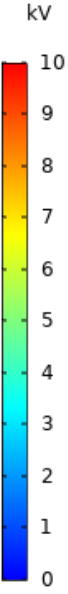

(a) (b)

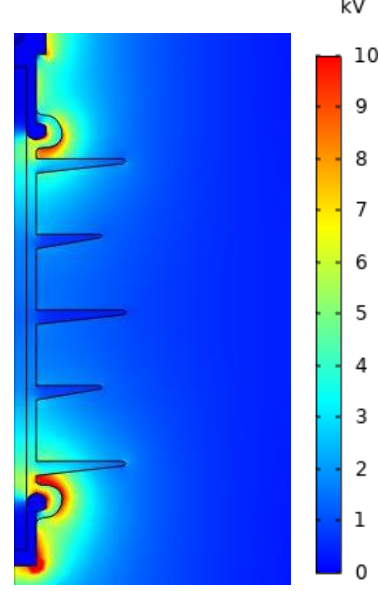

Fig 5: The electric field distribution a) model 1b) model 2

\subsection{D Electric models without pollution layer}

3D distribution of the generated electric field over the whole insulator the rainbow legend bar range between the maximum value $(11 \mathrm{kV})$ and the minimum value (ground) which is represented by the red color and blue respectively.

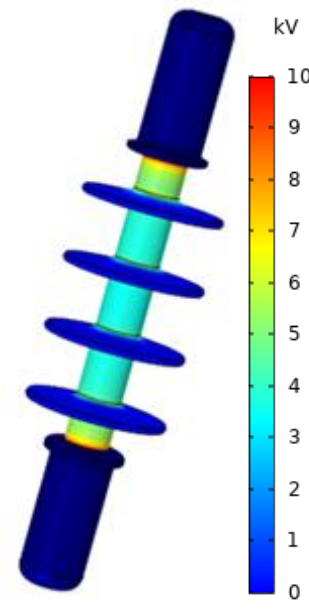

(a) (b)

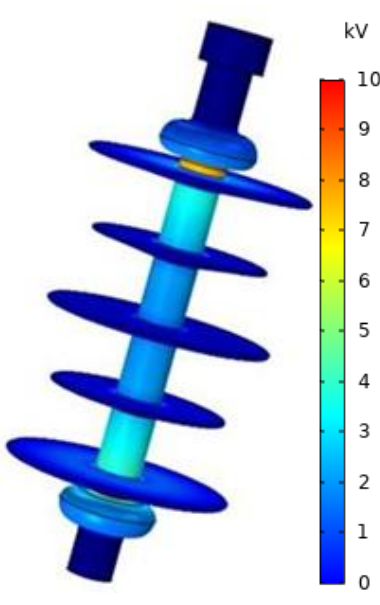

Fig 6: The 3D electric field distribution normal a) model 1 b) model 2

The 3D multi-slices of the generated an electric field over the whole insulator. The multi-slices are shown the distribution of the electric field inside the insulator.

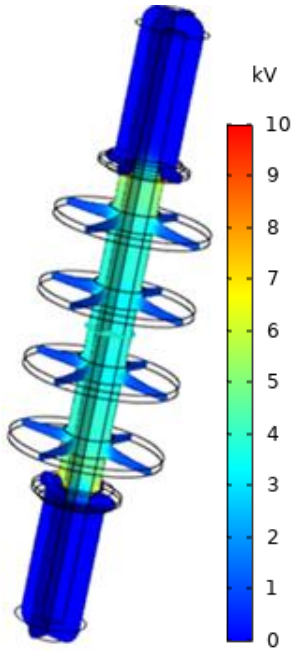

(a)

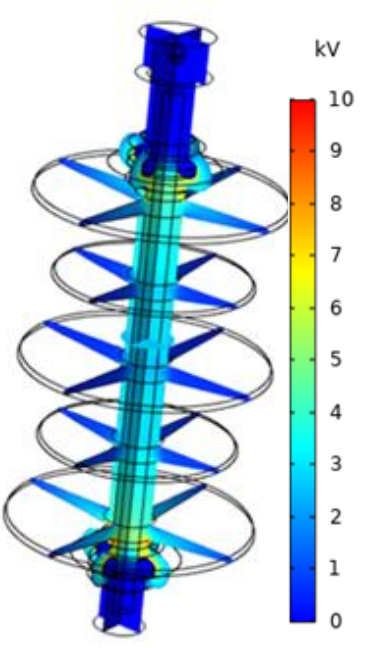

(b)
Fig 7: The 3D multi-slices of the generated electric field normal a) model 1 b) model 2

\subsection{D Electric field distributions with pollution layer}

The 3D distribution of the generated electric field over the whole insulator with the pollution layer is shown in figure 8 and Figure 9 shown the 3D multi-slices of the generated electric field over the whole insulator. The multi-slices are shown the distribution of the electric field inside the insulator with the pollution layer. 


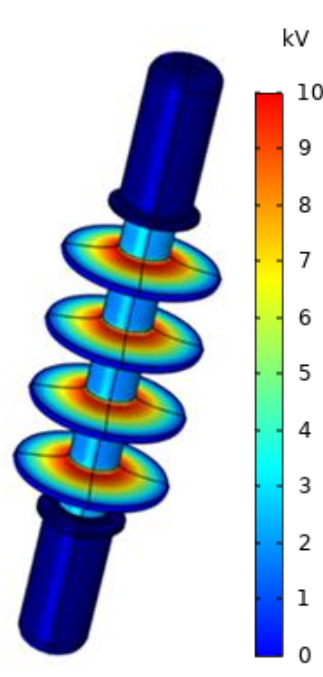

(a)

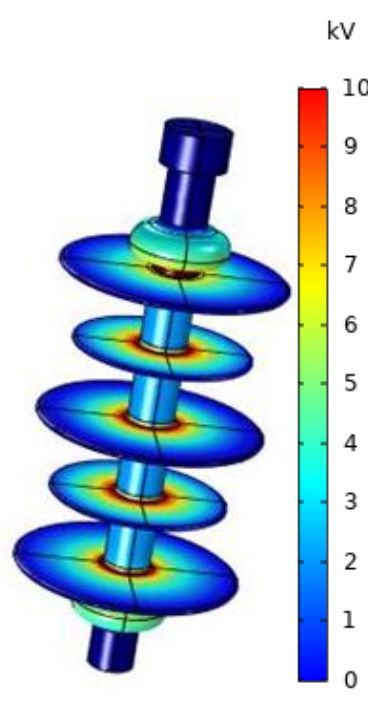

(b)
Fig 8: shows the 3D distribution of the generated electric field with pollution layer a) model 1 b) model 2

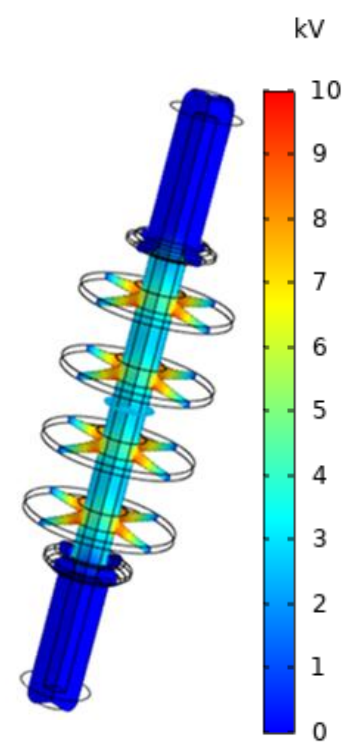

(a)

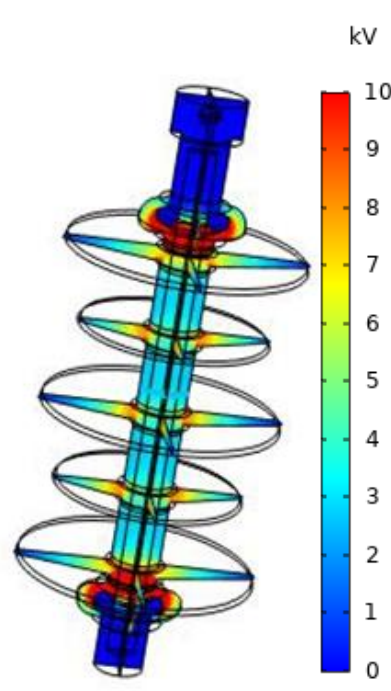

(b)
Fig 9: The 3D multi-slices of the generated electric field with pollution layer a) model 1 b) model 2

The E-field distributions along with the creepage distance of silicone rubber insulator under the pollution layer with nitrogen oxide are shown in figure 10.

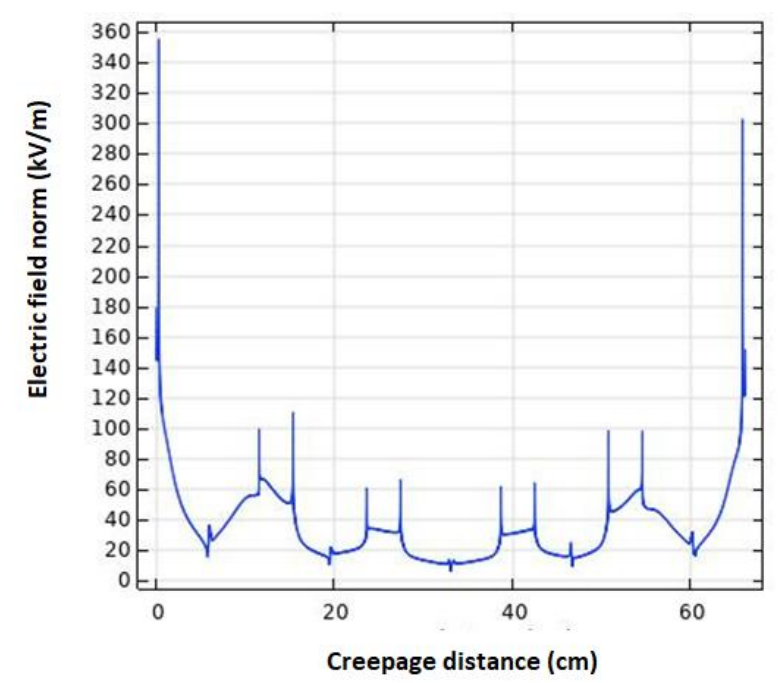

(a)

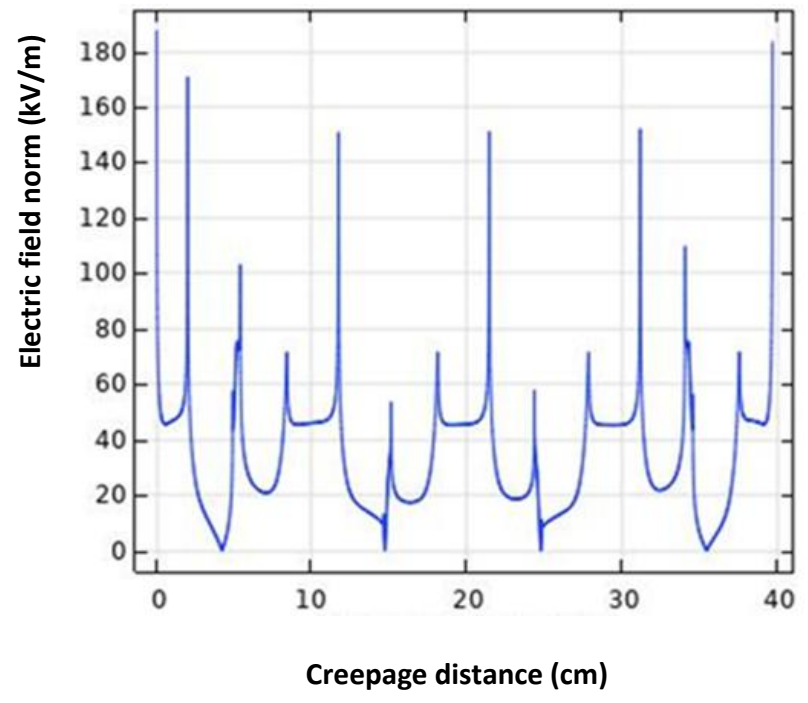

(b)

Fig 10: E-field distribution along creepage distance In case of a pollution layer a) model 1 b) model 2

The E-field distributions along with the creepage distance of silicone rubber insulator under the air polluted with nitrogen oxide are shown in figure 11. 


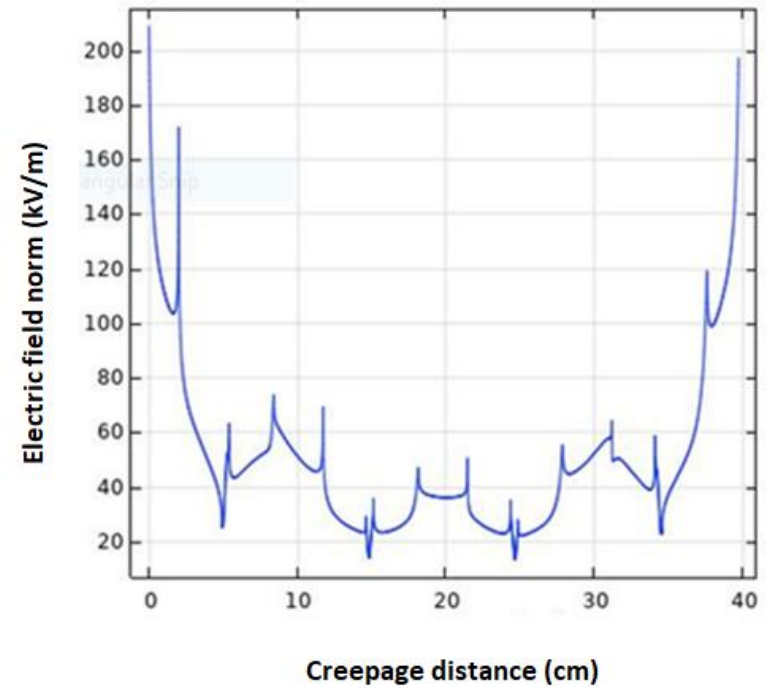

(a)

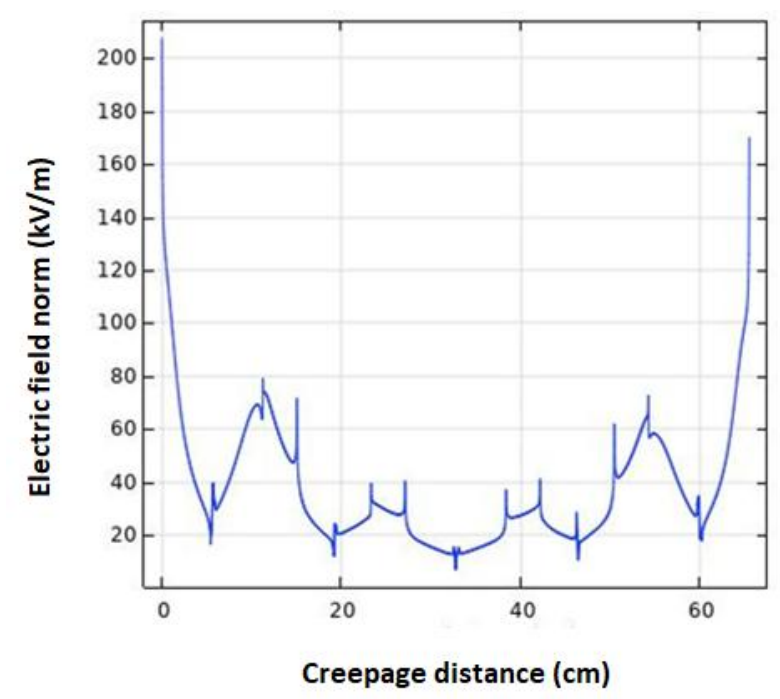

(b)

Fig 11: E-field distribution along creepage distance In case of air polluted a) model 1 b) model 2

The electric field along with the creepage distance in different conditions of pollution is shown in figure 12. However, the pollution is represented by a layer over the creepage distance. The thickness of this layer is considered the ignorance of periodic maintenance. The thickness of the pollution layer increases, the electric field increases.

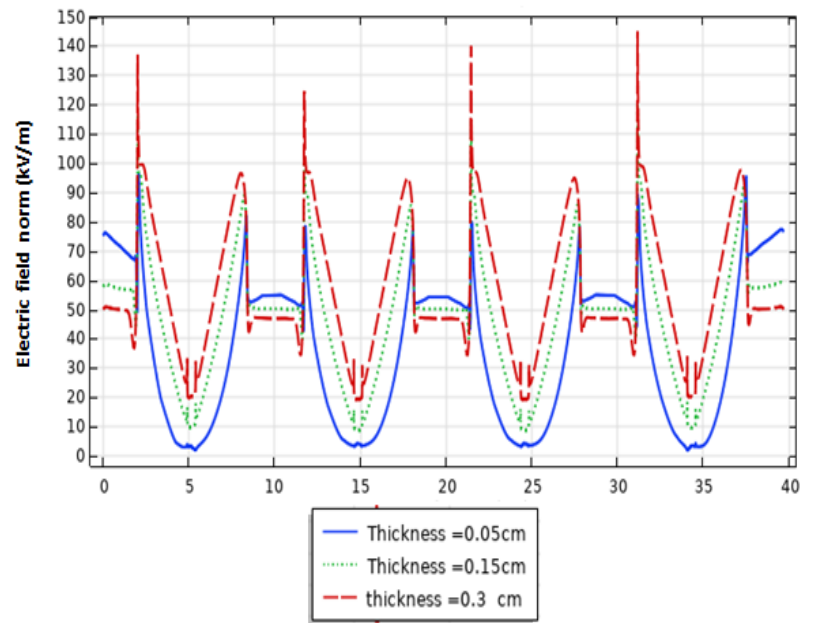

Creepage distance $(\mathrm{cm})$

Fig 12: comparison between different thicknesses of the pollution layer in term of the electric field over the creepage distance

A comparison between different weather conditions is performed as shown in figure 13 the first model and figure 14 the second model. However, the water-saturated sand causes the highest values of the generated electric field.

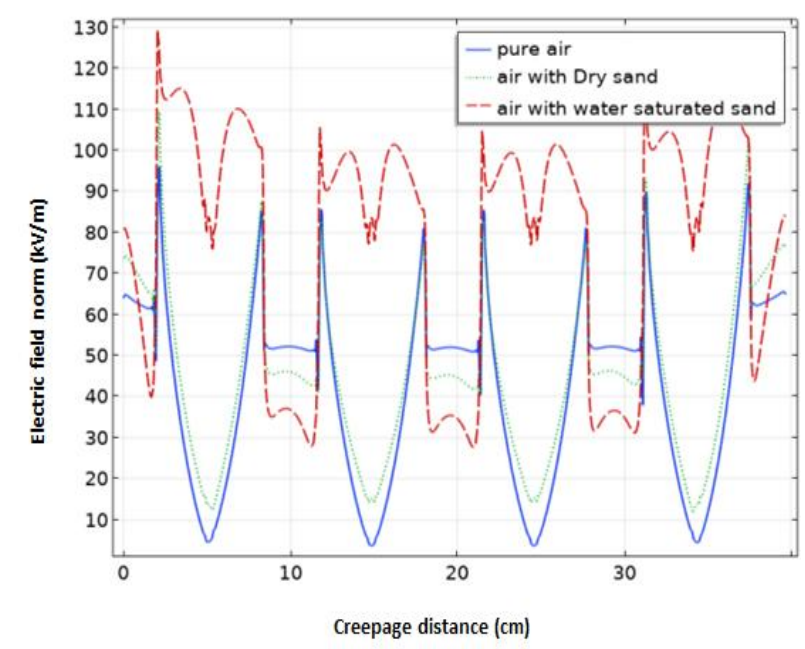

Fig 13: The effect of different types of pollution layer on the electric field over the creepage distance of model 1 


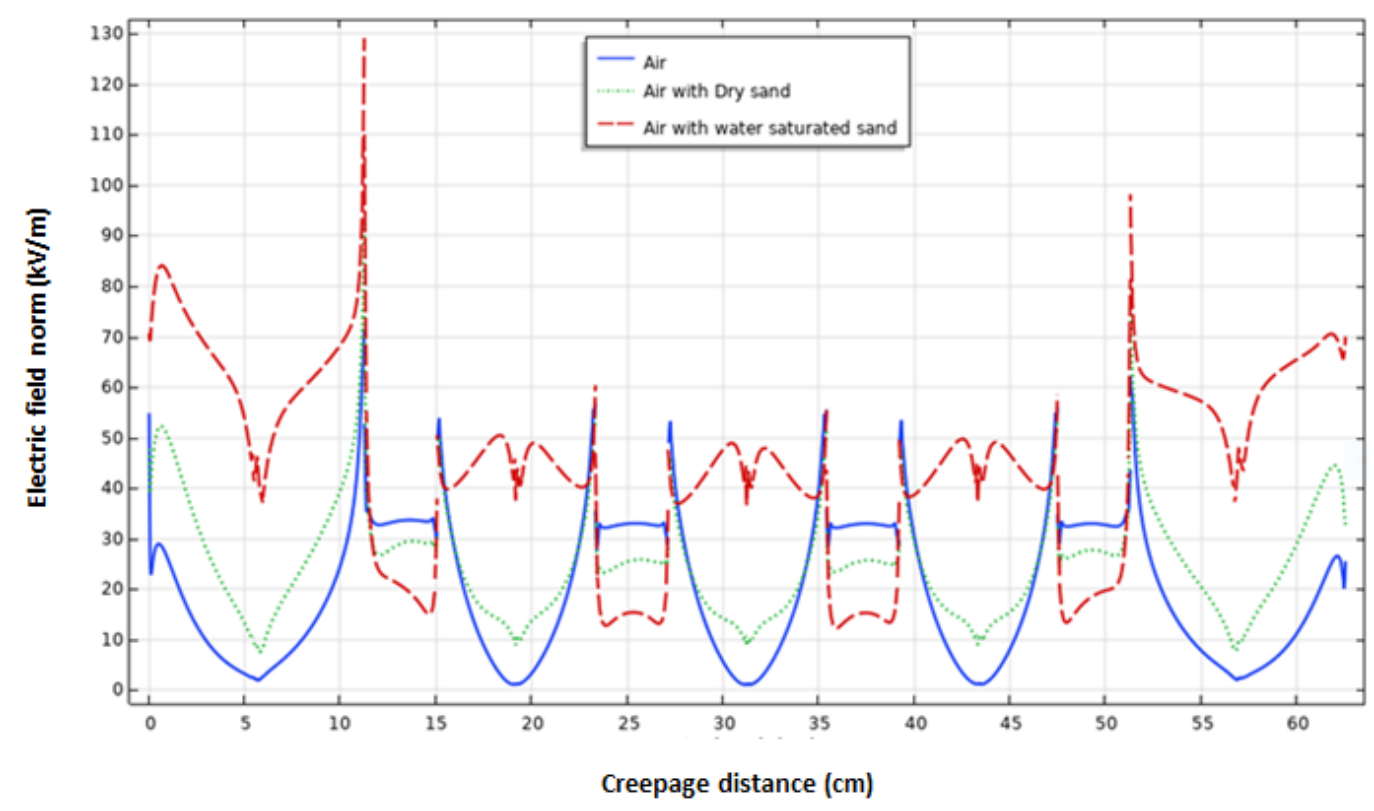

Fig 14: the effect of different types of pollution layer on the electric field over the creepage distance of model 2

A comparison between different pollution severities (light,

However, very heavy pollution causes the highest values. medium, heavy, and very heavy) is shown in figure 15.

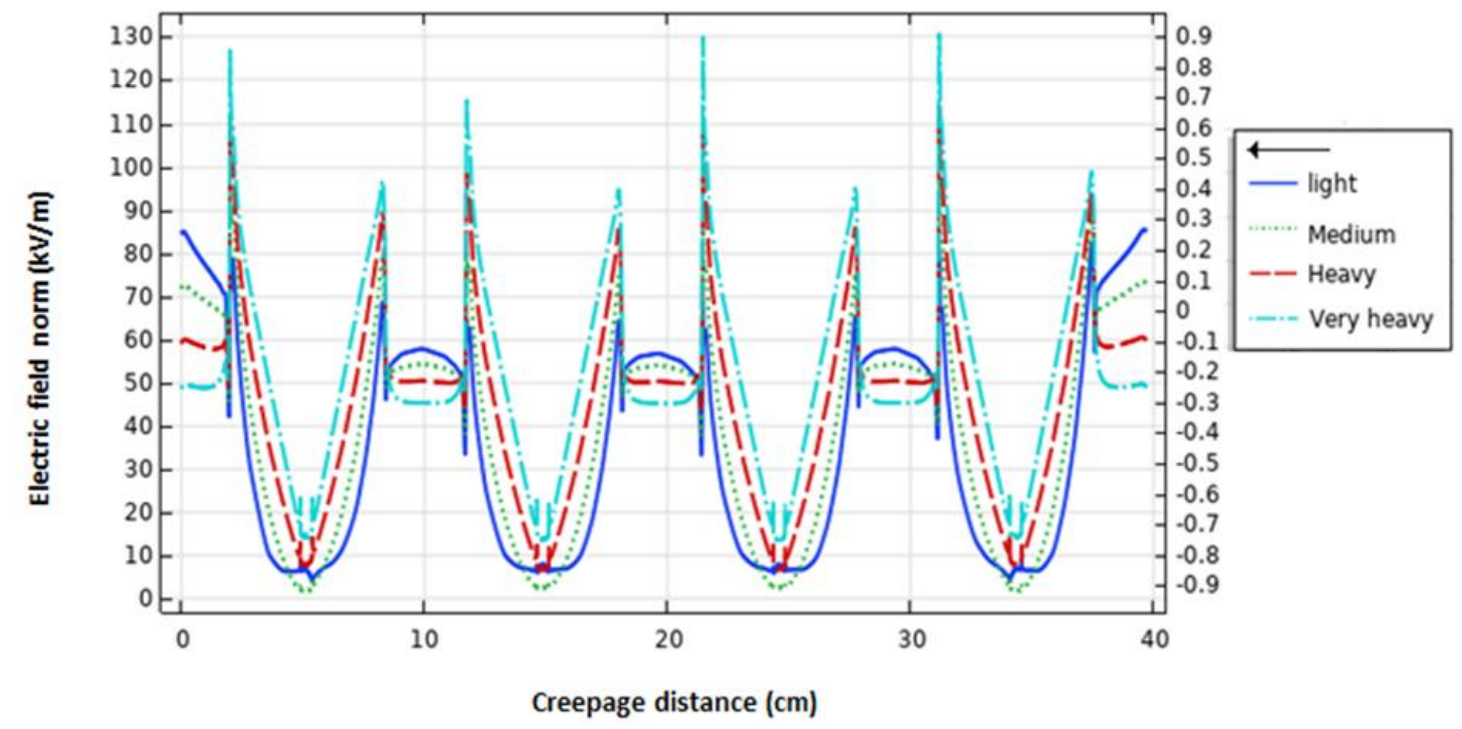

Fig 15: Comparison between different pollution severities

\section{CONCLUSION}

This paper investigates the simulation results of electric field distributions along the surface of silicone rubber insulators under the different types of pollution like (sand, watersaturated sand, and nitrogen oxide). Simulations were carried out using the finite element method (FEM) (COMSOL multiphasic 5.5). The proposed designs are built using COMSOL geometry tools. 2D axis symmetry as a spatial dimension is used to achieve $3 \mathrm{D}$ structure for more realism.

Where each a 3D model is revolved $\left(360^{\circ}\right)$ from the $2 \mathrm{D}$ plane. Two different models of composite insulator profiles of $11 \mathrm{kV}$ were studied. The first insulator model consists of four uniform sheds and the second insulator model consists of five alternating sheds. The maximum electric field in the first and second models when polluted with nitrogen dioxide is
$360 \mathrm{kV} / \mathrm{m}$ and $185 \mathrm{kV} / \mathrm{m}$ respectively, the maximum electric field in water-saturated sand is $130 \mathrm{kV} / \mathrm{m}$ in the first model and $129 \mathrm{kV} / \mathrm{m}$ in the second model, in case of air with dry sand $110 \mathrm{kV} / \mathrm{m}$ in the first mode and $90 \mathrm{kV} / \mathrm{m}$ in the second model, in pure air $95 \mathrm{kV} / \mathrm{m}$ in the first model and $73 \mathrm{kV} / \mathrm{m}$ in the second model. According to the explosion of ammonium nitrate, the maximum electric field in both models is 220 $\mathrm{kV} / \mathrm{m}$ when the air is polluted with nitrogen dioxide. And comparing between different pollution severities the electrical field is high when the pollution very heavy. The thickness of pollution varied from $0.05,0.15$, and $0.3 \mathrm{~cm}$. when the pollution layer thickness increased the electric field stress increased, and also when the electrical conductivity of the pollution layer increased the electric field stress increased. The alternating sheds insulators have the advantage over the uniform sheds due to many reasons, the strength of the 
electric field along with the creepage distance in the case of alternating insulators lower than the strength of the electric field along with the creepage distance in the case of the uniform insulators. This means that the loss of energy through the insulators is lower in the case of alternating sheds.

\section{REFERENCES}

[1] Zarzoura H. "Investigations on EHV insulator strings under desert environment "Ph. D. Thesis, Ain Shams University, 1981

[2] Working group, "A Survey of the problem of insulator contamination in the U.S.A. and Canada - part 1 - IEEE Trans. Pas - 90 - pp 2577 - 2585 (1971).

[3] Zedan , F., Akbar, M., Farag, A. and Zarzoura, H., "Insulator contamination research in saudi Arabia ",seminar on contamination problems in GCC states, GCC CIGRE, Bahrain,29-30/3/1989

[4] Rennie, I., Hamza, S., "EHT Overhead Line insulator problems in Qatar", Seminar on Contamination Problems in GCC states, GCC CIGRE, Bahrain, 29-30/3/1989

[5] Allbrahimi A., "Insulator contamination", Seminar on Contamination Problems in GCC states, GCC CIGRE,
Bahrain, 29-30/3/1989.

[6] Zarzoura H. "A new approach to the insulator contamination measurements in desert, IEEE, Paper No. A78121-6, 1978.

[7] B.A.Arafa, "Effect of Severe Sandstorms on the Performance of Polymeric Insulators", CIGRE 2012.

[8] Zoltán Török and Alexandru Ozunu," HAZARDOUS PROPERTIES OF AMMONIUM NITRATE AND MODELING OF EXPLOSIONS USING TNT EQUIVALENCY", November 2015, Vol.14, No. 11, 2671-2678.

[9] M. Kh. Mohamed, "Improving the Performance of Composite Insulators by Optimizing the Electric Field Distributions", PhD Thesis, Helwan university, 2016.

[10] Pryor, Roger W. Multiphysics modeling using COMSOL $®$ : a first principles approach. Jones \& Bartlett Publishers, 2009.

[11] T. Moriyoshi, T. Kita, and Y. Uosaki," Static Relative Permittivity of Carbon Dioxide and Nitrous Oxide up to $30 \mathrm{MPa}$ ", University of Tokushima, Tokushima 770, Japan 